\title{
Embryological and surgical considerations of absent infra-renal part of inferior venacava and left renal vein
}

\author{
Indira $\mathbf{C K}^{1}$, Arunkumar KG² \\ ${ }^{1}$ Associate Professor, Department of Anatomy, Government Medical College, Konni, Kerala, India, ${ }^{2}$ Assistant Professor, \\ Department of Anatomy, Government Medical College, Thrissur, Kerala, India
}

Background: Development of inferior vena cava (IVC) is a complex process that involves the anastomoses between three pairs of embryonic veins. Specific permutations exist in the venous plane of the abdomen and pelvis resulting in variations such as single left IVC, double IVC, and left renal retroaortic vein. Anomalies of the inferior vena cava and renal veins occur infrequently but may contribute to serious morbidity throughout surgical exploration if unidentified. Most anomalies remain asymptomatic until surgical intervention or clinical presentation with thromboembolic complications. Aims and Objective: Our research is aimed to link embryology with developmental disorder and the complications associated with the anomalous vessels in the field of surgery. Materials and Methods: Ten IUD fetuses (ranging from 20 weeks to term fetuses) were collected from the O\&G department of the college and injected locally with dilute formalin and placed in containers filled with formalin. Dissection of the fetuses was done to identify congenital anomalies. Results: The external appearance of the 28-week-old fetus showed no gross anomaly. Examination abdominal cavity showed absent infrarenal segment of IVC and left renal vein. The right renal vein was seen running a long course to the left side with tributaries of lumbar veins and was seen continuing as the left femoral vein medial to the femoral artery. Segments of suprarenal and renal IVC were present. Conclusion: Correlating anomalies and variations of IVC and its tributaries to embryology. However, understanding of such anomaly is necessary to avoid significant diagnostic pitfalls and in preoperative surgical and radiological intervention planning.

Key words: Anomalous; Embryology; Inferior Vena Cava (IVC); Surgery
Access this article online

Website:

http://nepjol.info/index.php/AJMS

DOI: 10.3126/ajms.v11i5.29744

E-ISSN: 2091-0576

P-ISSN: $2467-9100$

Copyright (c) 2020 Asian Journal of Medical Sciences

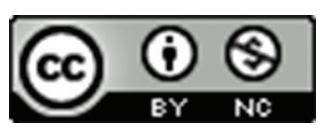

This work is licensed under a Creative Commons Attribution-NonCommercial 4.0 International License.

\section{INTRODUCTION}

It was early in the $20^{\text {th }}$ century that the variation in the anatomy of the inferior vena cava (IVC) and renal veins was first noticed. An understanding of the related embryology is the best way to comprehend the abnormalities observed. IVC and renal venous embryogenesis is complex. ${ }^{1}$

The retroperitoneal venous system emerges from three paired venous fetal systems. These are the posterior cardinal, the subcardinal, and the supracardinal systems which arise in a chronological order, the posterior cardinal being dominant at 6 weeks, the subcardinal at 7 weeks and the supracardinal at about 8 weeks. The subcardinal system develops to the prerenal segment of IVC. ${ }^{2}$

Renal vein develops from anastomosis between the subcardinal and supracardinal systems. The supracardinal venous system develops to postrenal segment of the IVC under the diaphragm. ${ }^{3}$

\section{Embryology}

IVC is a composite vessel in the adult which develops in the posterior abdominal wall dorsal to the developing peritoneal cavity. IVC develops by temporal remodelling of venous complexes during the $6^{\text {th }}$ to $10^{\text {th }}$ week of 
gestation. ${ }^{1}$ The formation of the postrenal segment (infrarenal part) of IVC is still not clearly described. The function of IVC is initially carried out by the postcardinal veins of either sides of body. The postcardinal veins communicate via inter-post cardinal anastomosis in early stage. ${ }^{1}$ The left sided veins divert more blood towards right side and hence the left sided cardinal veins regress towards later stage. At different gestational period, three parallel pairs of cardinal veins form anastomotic channels among themselves and undergo partial regression. The remaining parts of these venous channels coalesce to form the adult IVC and the bifurcation of the iliac veins. The first pair of veins to form are the postcardinal veins on the posterior abdominal wall of the fetus. Except for the more distal part which becomes the iliac bifurcation, this system completely regresses. The subcardinal veins are situated anterior and medial to the postcardinal veins. The left subcardinal vein regresses fully and the right channel forms the suprarenal segment of IVC. The supracardinal veins are located directly behind the aorta. The left supracardinal system regress and the right remains to form the infrarenal segment of IVC. Both the subcardinal system and the supracardinal system form extensive anastomotic channels at the level of renal vein.

These channels coalesce to form broad anterior and posterior vein which drains the left kidney and binds to the IVC. The vein posterior to the aorta eventually regresses but the vein anterior to the aorta persists to become the left renal vein. In summary, the right subcardinal vein forms a suprarenal segment (prerenal segment) of the IVC, the right supracardinal vein forms infrarenal (post renal) segment, the postcardinal veins form an iliac bifurcation, and both the subcardinal and supracardinal systems contribute to the formation of the renal veins. With such a complex embryogenesis process, IVC anomalies routinely occur. There are about 15 different IVC anomalies recorded, but many are minor variations..$^{4-6}$

\section{Commonly reported anomalies of IVC}

Isolated left IVC result from persistence of left supracardinal vein and its reported in $0.2-0.5 \%$ population ${ }^{7}$ Double IVC results from persistence of both supracardinal veins ${ }^{7,8}$ Failure of subcardinal anastomosis leads to azygous and hemiazygous continuation of IVC. ${ }^{7,8}$

Circumaortic renal vein and defective posterior subcardinal anastomosis leads to variation in left renal vein. ${ }^{7.8}$

Surgical significance of vena caval and renal vein anomalies

Anomalous venous complexes tend to dilate and become tortuous resulting in hemorrhage, which may be fatal. Unascended, malrotated or horse- shoe kidneys tend to have anomalous renal vein or IVC. Duplicate IVC or thrombus in IVC ${ }^{9}$ may require protection with filter. ${ }^{10}$

Therefore, the current study is aim to developmental anomalies of IVC and its complications in surgical field.

\section{MATERIALS AND METHODS}

Ten IUD fetuses were collected in the college from $O \& G$ department and dissected to study abnormal retroperitoneal vessels. Fetuses ranging from 20 weeks gestational age to term fetuses were collected and injected with dilute formalin locally and kept in containers filled with formalin. Dissection of fetuses was performed to identify congenital abnormalities. In this case $\left(28^{\text {th }}\right.$ week gestational age) midline incision was put in the abdomen extending from xiphoid process to pubic symphysis. As noted, incision was further extended to lower limb along mid-inguinal point downward to trace the veins. Since the veins were slender, they were traced with utmost care.

\section{RESULTS}

The external features did not have significant anomalous appearance in the 28th week-old fetus. On dissecting the abdomen for retroperitoneal vessels, infra-renal portion of IVC was not observed. The right renal vein was seen following a long path to the left, joined by lumbar veins on the left side and was seen in continuity as the left femoral vein medial to the femoral artery. Ureters of both sides were seen draining to urinary bladder. Figure 1 showing absent infra-renal part of IVC. Vertebral column seen behind aorta with absent IVC. Figure 2 showing left kidney, ureter, left renal artery and absent left renal vein, Prerenal IVC is seen, Figure 3 showing anomalous right renal vein and inferior venacava. Figure 4 showing left renal vein crossing to left side and lying medial to left femoral artery.

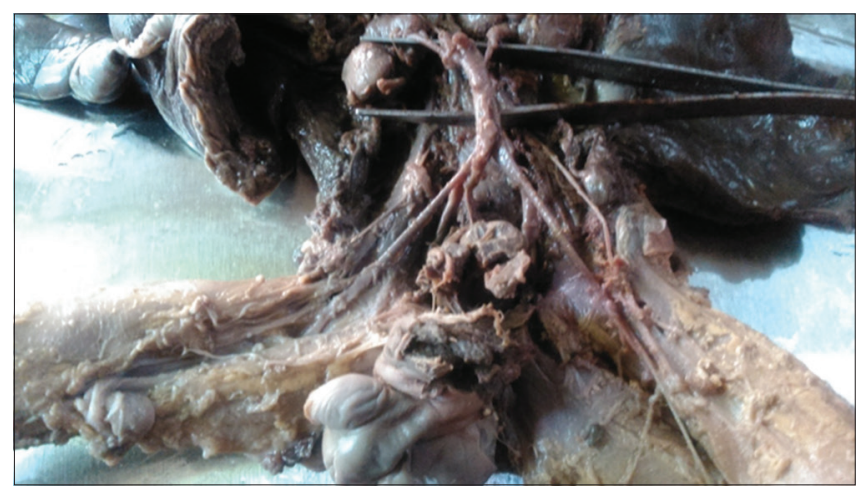

Figure 1: Image showing absent infra-renal part of IVC. Vertebral column seen behind aorta with absent IVC 


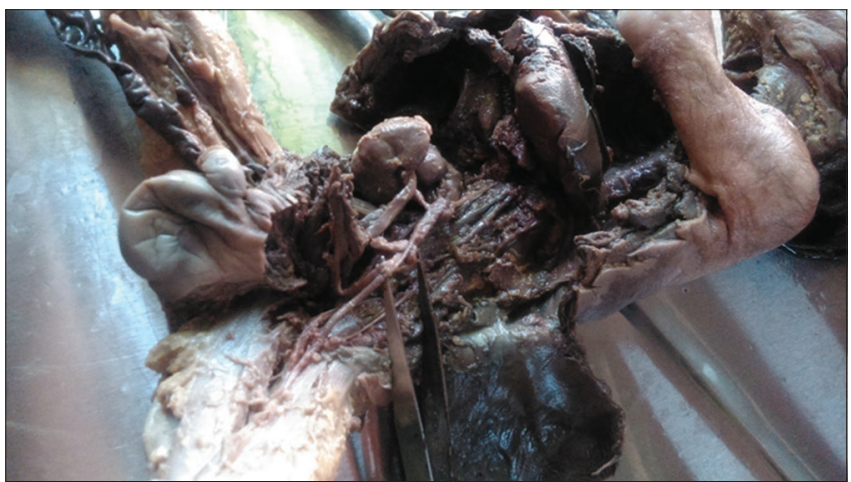

Figure 2: Image showing left kidney, ureter, left renal artery and absent left renal vein. Prerenal IVC is seen

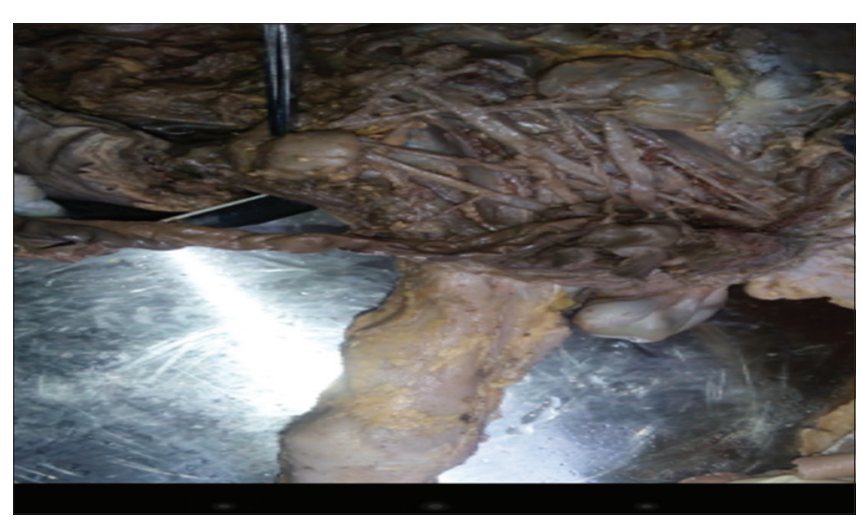

Figure 3: Image showing anomalous right renal vein crossing to left side

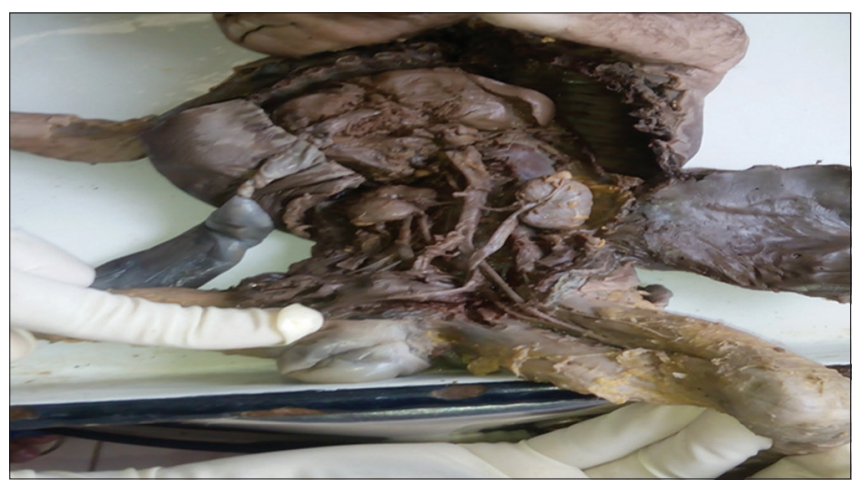

Figure 4 : left renal vein crossing to right side

\section{DISCUSSION}

IVC anomalies are manifestations of complex developmental process. A surgeon needs to be aware of the potential problems arising from IVC anomalies. Nephrectomy, adrenalectomy and sympathectomy in a patient with IVC anomalies may be dangerous. Patient with double IVC, the IVC may be intervened with either a filter or plication to avoid pulmonary emboli. Although rare, IVC anomalies may present challenges for the surgeon, who operates on retroperitoneal structures.
Congenital defect of IVC occurs at six to eight weeks gestation due to an anomalous embryonic growth of the supracardinal vein, subcardinal vein and supracardinalsubcardinal anastomosis. ${ }^{11}$ The maldevelopment of the supracardinal vein results in absent infrarenal part of IVC. Defective subcardinal vein gives rise to absent or defective suprarenal portion of inferior venacava and renal veins. The renal segment of inferior venacava and common iliac veins is derived from posterior cardinal vein. ${ }^{11}$

In this case, the absence of infra-renal part of IVC suggests anomalous right supra-cardinal venous development which resulted in absence of infra-renal part of IVC. Since renal veins develop from supracardinal- subcardinal anastomosis that forms a dorsal arch of the aortic collar, the absence of the left renal vein and the anomalous right renal vein suggest defective anastomosis between the supracardinal and subcardinal veins. In this case, the continuity of the right renal vein with lumbar veins and continuing as left femoral vein to the left side indicates a defect in the posterior cardinal anastomosis and persistence of the left posterior cardinal vein. Anomalous anastomosis existed between left supracardinal vein and left posterior cardinal vein. The anomalous link between left supracardinal and right subcardinal vein lead to right renal vein crossing to left and continuing as left femoral vein.

Perinatal inferior venacava thrombosis result in hypoplasia or absence of inferior venacava. ${ }^{12}$ The dilated right renal vein indicates its possibility for developing thrombosis. The etiology of absent infra-renal IVC is unclear according to the above author. ${ }^{12}$ The author suggests that dysgenesis of the right supracardinal vein may be a possible mechanism, and also includes that a single embryological event does not fully explain the absence of infrarenal IVC.

\section{Surgical correlation}

It's found that in 5 per cent young people, deep vein thrombosis is associated with inferior venacava abnormalities. It is assumed that venous return with an anomalous inferior venacava is insufficient and can lead to venous stasis in the lower limb that may precipitate thrombosis. ${ }^{13}$ IVC abnormalities may be associated with congenital anomalies in organs such as liver, heart, and lung, because embryological development occurs during the same time. ${ }^{11}$ IVC dysfunction is also associated with dextrocardia, atrial septal defect, atrioventricular canal, pulmonary artery stenosis. ${ }^{14}$ Patients with congenital anomalous IVC often suffer from frequent non-healing venous ulcers. ${ }^{15}$ Huntington and McLure proposed almost 14 theoretical variations in the IVC infra-renal section. Patients with absent IVC segments can develop venous insufficiency symptoms in lower limbs. ${ }^{16}$ 


\section{CONCLUSION}

Although anomalies in the venacava are rare, preoperative identification can prevent morbidity and enable better planning of operational procedures. This knowledge is particularly relevant in circumstances involving surgeries of the venous system. During preoperative examination, it is important to take adequate precautions in identifying anatomical anomaly save injury.

\section{ACKNOWLEDGEMENT}

The author is thankful to the Department of Anatomy and Gynaecology, Government Medical College, Thrissur, Kerala favouring to conduct of the present study.

\section{REFERENCES}

1. Bass JE, Redwine MD, Kramer LA, Huynh PT and Harris Jr JH. Spectrum of Congenital Anomalies of the Inferior Vena Cava: Cross-sectional Imaging Findings 1: (CME available in print version and on RSNA Link). Radiographics. 2000;20(3):639-652. https://doi.org/10.1148/radiographics.20.3.g00ma09639

2. Giordano JM and Trout III HH. Anomalies of the inferior vena cava. Journal of vascular surgery. 1986;3(6):924-928. https://doi.org/10.1016/0741-5214(86)90162-X

3. Clayman RV, Gonzalez R and Fraley EE. Renal cell cancer invading the inferior vena cava: clinical review and anatomical approach. The Journal of urology. 1980;123(2):157-163. https://doi.org/10.1016/S0022-5347(17)55832-2

4. Natsis K, Apostolidis S, Noussios G, Papathanasiou E, Kyriazidou A and Vyzas V. Duplication of the inferior vena cava: anatomy, embryology and classification proposal. Anatomical science international. 2010;85(1):56-60.

https://doi.org/10.1007/s12565-009-0036-z

5. Friedland GW, deVries PA, Nino-Murcia M, King BF, Leder RA and Stevens $\mathrm{S}$. Congenital anomalies of the inferior vena cava: embryogenesis and MR features. Urologic radiology. 1991;13(1):237.

https://doi.org/10.1007/BF02924631
6. Campbell M and Deuchar DC. Absent inferior vena cava, symmetrical liver, splenic agenesis, and situs inversus, and their embryology. British Heart Journal. 1967;29(2):268.

https://doi.org/10.1136/hrt.29.2.268

7. Malaki M, Willis AP and Jones RG. Congenital anomalies of the inferior vena cava. Clinical radiology. 2012;67(2):165-171. https://doi.org/10.1016/j.crad.2011.08.006

8. Shindo S, Kubota K, Kojima A, Iyori K, Ishimoto T, Kobayashi M, et al. Anomalies of inferior vena cava and left renal vein: risks in aortic surgery. Annals of vascular surgery. 2000;14(4):393-396. https://doi.org/10.1007/s100169910071

9. Christison-Lagay E and Fishman SJ. Vascular anomalies. In Pediatric Surgery 2009 (pp. 659-671). Springer, Berlin, Heidelberg. https://doi.org/10.1007/978-3-540-69560-8_68

10. Singhal R and Brimble KS. Thromboembolic complications in the nephrotic syndrome: pathophysiology and clinical management. Thrombosis research. 2006;118(3):397-407. https://doi.org/10.1016/j.thromres.2005.03.030

11. Cho BC, Choi HJ, Kim SK, Lee YW, Lee DH, Hong YK, et al. Congenital absence of inferior vena cava as a rare cause of pulmonary thromboembolism. Yonsei Med J. 2004;45(5):947-951. doi: 10.3349/ymj.2004.45.5.947. 10.1067/mva.2001.114205

12. Ramanathan $T$, Michael $T$, Hughes $D$ and Richardson AJ. Perinatal inferior vena cava thrombosis and absence of the infrarenal inferior vena cava. Journal of vascular surgery. 2001;33(5):1097-1099. https://doi.org/10.1067/mva.2001.114205

13. Iqbal $\mathrm{J}$ and Nagaraju E. Congenital absence of inferior vena cava and thrombosis: a case report. Journal of medical case reports. 2008;2(1):46.

https://doi.org/10.1186/1752-1947-2-46

14. Timmers GJ, Falke TH, Rauwerda JA and Huijgens PC. Deep vein thrombosis as a presenting symptom of congenital interruption of the inferior vena cava. International journal of clinical practice. 1999;53(1):75-76. PMID:10344071

15. Gupta A, Kumar S and Kothari SS. Congenital absence of infrarenal inferior vena cava and deep veins of the lower limbs: a case report. Journal of medical case reports. 2016;10(1):218. https://doi.org/10.1186/s13256-016-1015-3

16. Petik $B$. Inferior vena cava anomalies and variations: imaging and rare clinical findings. Insights into imaging. 2015;6(6):631-639. https://doi.org/10.1007/s13244-015-0431-z

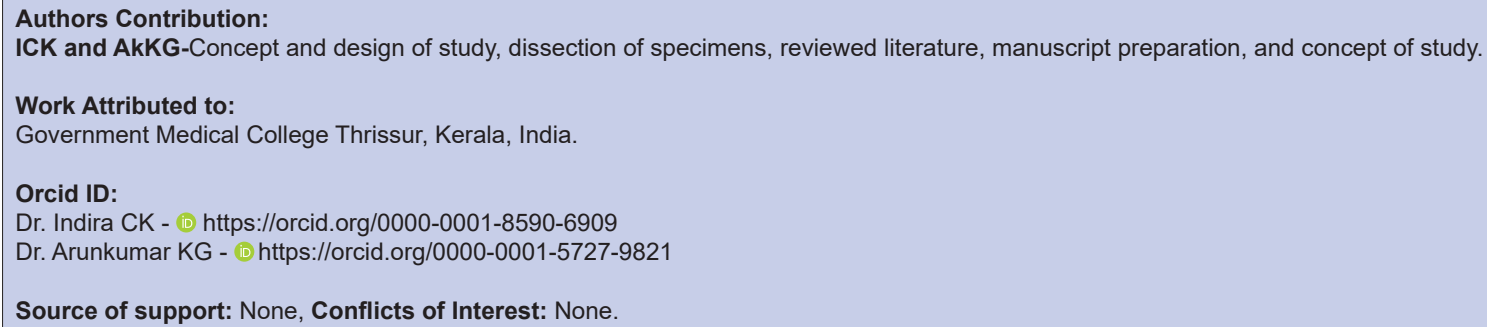

